\title{
Effects of a progressive aquatic resistance exercise program on the biochemical composition and morphology of cartilage in women with mild knee osteoarthritis: protocol for a randomised controlled trial
}

Benjamin Waller ${ }^{1 *}$, Matti Munukka1, Juhani Multanen¹, Timo Rantalainen'1, Tapani Pöyhönen ${ }^{1,2}$, Miika T Nieminen ${ }^{3,4}$,

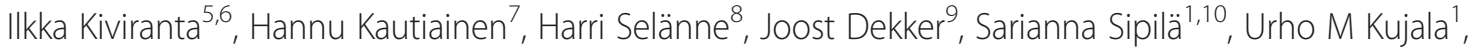
Arja Häkkinen ${ }^{1,11}$ and Ari Heinonen ${ }^{1}$

\begin{abstract}
Background: Symptoms associated with osteoarthritis of the knee result in decreased function, loss of working capacity and extensive social and medical costs. There is a need to investigate and develop effective interventions to minimise the impact of and even prevent the progression of osteoarthritis. Aquatic exercise has been shown to be effective at reducing the impact of osteoarthritis. The purpose of this article is to describe the rationale, design and intervention of a study investigating the effect of an aquatic resistance exercise intervention on cartilage in postmenopausal women with mild knee osteoarthritis.
\end{abstract}

Methods: A minimum of 80 volunteers who meet the inclusion criteria will be recruited from the local population through newspaper advertisements. Following initial assessment volunteers will be randomised into two groups. The intervention group will participate in a progressive aquatic resistance exercise program of 1-hour duration 3 times a week for four months. The control group will be asked to maintain normal care during this period. Primary outcome measure for this study is the biochemical composition of knee cartilage measured using quantitative magnetic resonance imaging; T2 relaxation time and delayed gadolinium-enhanced magnetic resonance imaging techniques. In addition, knee cartilage morphology as regional cartilage thickness will be studied. Secondary outcomes include measures of body composition and bone traits using dual energy $\mathrm{x}$-ray absorptiometry and peripheral quantitative computed tomography, pain, function using questionnaires and physical performance tests and quality of life. Measurements will be performed at baseline, after the 4-month intervention period and at one year follow up.

Discussion: This randomised controlled trial will investigate the effect a progressive aquatic resistance exercise program has on the biochemical composition of cartilage in post-menopausal women with mild knee osteoarthritis. This is the first study to investigate what impact aquatic exercise has on human articular cartilage. In addition it will investigate the effect aquatic exercise has on physical function, pain, bone and body composition and quality of life. The results of this study will help optimise the prescription of aquatic exercise to persons with mild knee osteoarthritis.

Trial registration: ISRCTN65346593.

Keywords: Osteoarthritis, Quantitative MRI, T2 relaxation time, dGEMRIC, Bone, Aquatic exercise

\footnotetext{
* Correspondence: ben.waller@jyu.fi

'Department of Health Sciences, University of Jyväskylä, Jyväskylä, Finland

Full list of author information is available at the end of the article
} 


\section{Background}

Osteoarthritis (OA) of the lower limb is a leading cause of decreased function and quality of life [1]. It has been estimated that the prevalence of symptomatic OA of the knee is between $7-33 \%$ with an increase in prevalence with age and is the most common site of symptomatic OA [2-6]. Early signs of OA in articular cartilage, which is constituent for the initiation and progression of OA, are characterised with loss of proteoglycans, breakdown of the collagen matrix and increased water content [7]. As the disease progresses there is fibrillation of the cartilage, changes in the subchondral bone, formation of osteophytes and thickening of the synovium [8-11] and as such OA is considered a whole joint disease. These modifications within the joint lead to the gradual development of clinical symptoms such as stiffness, decreased range of motion and pain [12] which cause a decrease in joint proprioception [13] and inhibits muscle activation $[14,15]$ leading to a decrease in activity. This disuse results in a lowering of aerobic capacity, muscle strength and muscle mass and ultimately a decrease in functional capacity and increased dependence $[16,17]$. Additionally, reduced muscle strength is a risk factor for future pain [17], self-reported knee instability [18] and increased risk of falling [19]. These in combination cause the extensive social and medical costs to society as a direct or indirect result of OA.

Although there is no known cure for OA the diseaserelated factors such as impaired muscle function and reduced aerobic fitness can be improved and maintained with therapeutic exercise $[20,21]$. Previous systematic reviews have demonstrated that exercise has positive effects on pain and function for people with symptomatic OA of the knee [21-23] and is recommended as one of the primary non-pharmaceutical treatment modalities in current OA guidelines [24-29]. Exercising in water is also strongly recommended in these guidelines. There is evidence to suggest that therapeutic aquatic exercise has a short term positive effect on pain and function in persons with OA of knee and/or hip similar to that of land training [30,31]. There is good evidence to support the use of strength exercises in the management of symptoms resulting from OA [32] however, there is conflicting evidence that therapeutic aquatic exercises can improve strength of lower limb muscles in persons with OA [33-40]. It is thought that the benefits from aquatic exercise are primarily a result of the decreased effects of gravity. Buoyancy reduces compressive and shear forces on joints and thus offers a comfortable training medium for patients with OA [41].

Previously, one restriction in OA research was the lack of non-invasive in vivo techniques to quantify the structure and acute changes in cartilage. Advances in magnetic resonance imaging (MRI) have made mapping of the articular cartilage and loading related changes possible [42]. The "delayed Gadolinium Enhanced MRI of Cartilage" (dGEMRIC) technique utilizes a paramagnetic contrast agent gadolinium (Gd-DTPA ${ }^{2-}$ ) to detect early reduction of glycosaminoglycan (GAG) from the matrix, a phenomenon considered to represent the onset of the degenerative process of cartilage [43]. Measurement of T2 relaxation time, sensitive to degeneration of tissue collagen and the orientation of collagen fibres in the extracellular matrix, has been developed to detect early degeneration or senescent changes of cartilage $[44,45]$. In addition, the assessment of morphological properties from three-dimensional MRI measurements enables assessment of tissue changes at a macroscopic scale [46] which have been found to be reliable, responsive and valid methods for mapping the volumetric data of articular cartilage [47-49].

There is still a lack of evidence that human cartilage can adapt to mechanical loading in a similar way to other tissues such as bone and muscle. Animal studies have suggested that physical exercise can improve tissue integrity by increasing the GAG content and indentation stiffness in load bearing cartilage [50,51]. In a crosssectional study Tiderius et al. [52] concluded, based on dGEMRIC measurements, that GAG content was higher in regularly exercising individuals than in sedentary subjects. Additionally, observations by Teichtahl et al. [53] suggest that vigorous physical activity is associated with a reduced rate of patella cartilage volume loss in asymptomatic subjects. To date, only one randomised intervention study investigating the direct effect of exercise on biochemical composition of human cartilage [54] has been published. Roos et al. [54] reported a positive effect of a moderate four months exercise on the GAG content, measured with dGEMRIC in subjects with high risk of knee OA. Another study by Cotofana et al. [55] provides no evidence that a 3-month exercise intervention in untrained middle-aged women can significantly alter cartilage morphology in the knee joint. Furthermore, the optimal type or intensity of exercise for improvement in cartilage is not known and longitudinal effects of training are needed to determine the exercise response once $\mathrm{OA}$ is established. In particular, there are no studies investigating the effect non-impact training such as therapeutic aquatic exercise has on the structures related to and progression of OA in the knee joint.

Therefore we plan to investigate the effects of an intensive aquatic resistance exercise program on the biochemical composition and morphology of the knee cartilage as well as its effect on physical function in postmenopausal women with mild knee osteoarthritis. In addition, we plan to discover if the possible benefits of exercise on cartilage, symptoms and physical function can be maintained one year after training period. 
The purpose of this article is to describe the rationale, design and intervention of a study investigating the effect an aquatic resistance exercise intervention has on the cartilage in postmenopausal women with mild knee osteoarthritis.

\section{Methods and design Study design}

The design of this study will be a 4-month randomised controlled exercise intervention study (RCT) with a 16 month follow up (Trial registration: ISRCTN65346593). After baseline measurements the voluntary participants will be randomly assigned into the two arms of the study, an aquatic resistance strength training group and a control group. All the outcome measurements will be performed at baseline, after the 4-month intervention and at follow up 12 months after cessation of training.

\section{Participants and selection criteria}

Volunteer postmenopausal women, between the ages of 60-68 year-old, will be recruited through a series of local newspaper advertisements and will be gathered from the county of Central Finland which has a population of approximately 275000 . Inclusion eligibility, (see below), will be initially assessed using a structured telephone interview. The telephone questionnaire includes questions concerning degree of knee pain, current level of physical activity and past medical history.

Suitable participants will be taken forward and they will undergo weight bearing $\mathrm{x}$-ray imaging of both knees. An experienced radiologist and orthopaedic physician will assess the images grading the degree of $\mathrm{OA}$ in the tibiofemoral and patellofemoral joints using the Kellgren-Lawrence grading (K/L 0-IV) [56]. Those participants who have a KL score of I (possible osteophytes) or II (definite osteophytes, possible joint space narrowing), will be included in the next stage of eligibility assessment and undergo a medical and physiotherapy screening. At this point any possible physical or medical limitations to full participation in the intervention will be assessed e.g. severely restricted joint range of movement (ROM), excessive laxity of knee joint, possible physical disabilities and abnormalities found from resting echocardiogram.

Subjects will be excluded if they have at least one of the following criteria; $\mathrm{BMI}>34$, resting pain in knee VAS > $50 / 100$, known loose particles in knee joint, acute inflammation in knee joint, knee intra-articular steroid injection in previous 3 months or oral steroid medication treatment in the previous 12 months, undergoing treatment for osteoporosis or T-score for femoral neck bone mineral density (BMD, $\mathrm{g} / \mathrm{cm}^{2}$ ) lower than -2.5 i.e. indicating osteoporosis as measured with DXA [57-59], previous cancer or radiotherapy, suffer from type I or II diabetes, cardiac disease, diagnosed rheumatic disease (other than $\mathrm{OA}$ ), undergone surgical procedure to knee (excluding menisectomy or arthroscopy if over 12 months ago) or joint replacement surgery in lower limbs.

Additional exclusion criteria are problems that would prevent MRI imaging, including electronic or magnetic implants e.g. pace maker, metal within body e.g. internal bone fixations, artificial aortic heart valve, metal particles in eyes, large tattoos on lower limb, claustrophobia or possible allergy to the contrast medium. Further, fasting blood samples will be taken to analyse Krea to ensure kidney function for normal removal of contrast medium from the body. All those participants fulfilling all the inclusion criteria will be included into the study and undergo the baseline measurements. Figure 1 shows the flow chart describing the selection and measurement procedure for the whole study.

\section{Sample size}

The sample size and power calculations have been estimated for the primary end points of this study, i.e. the

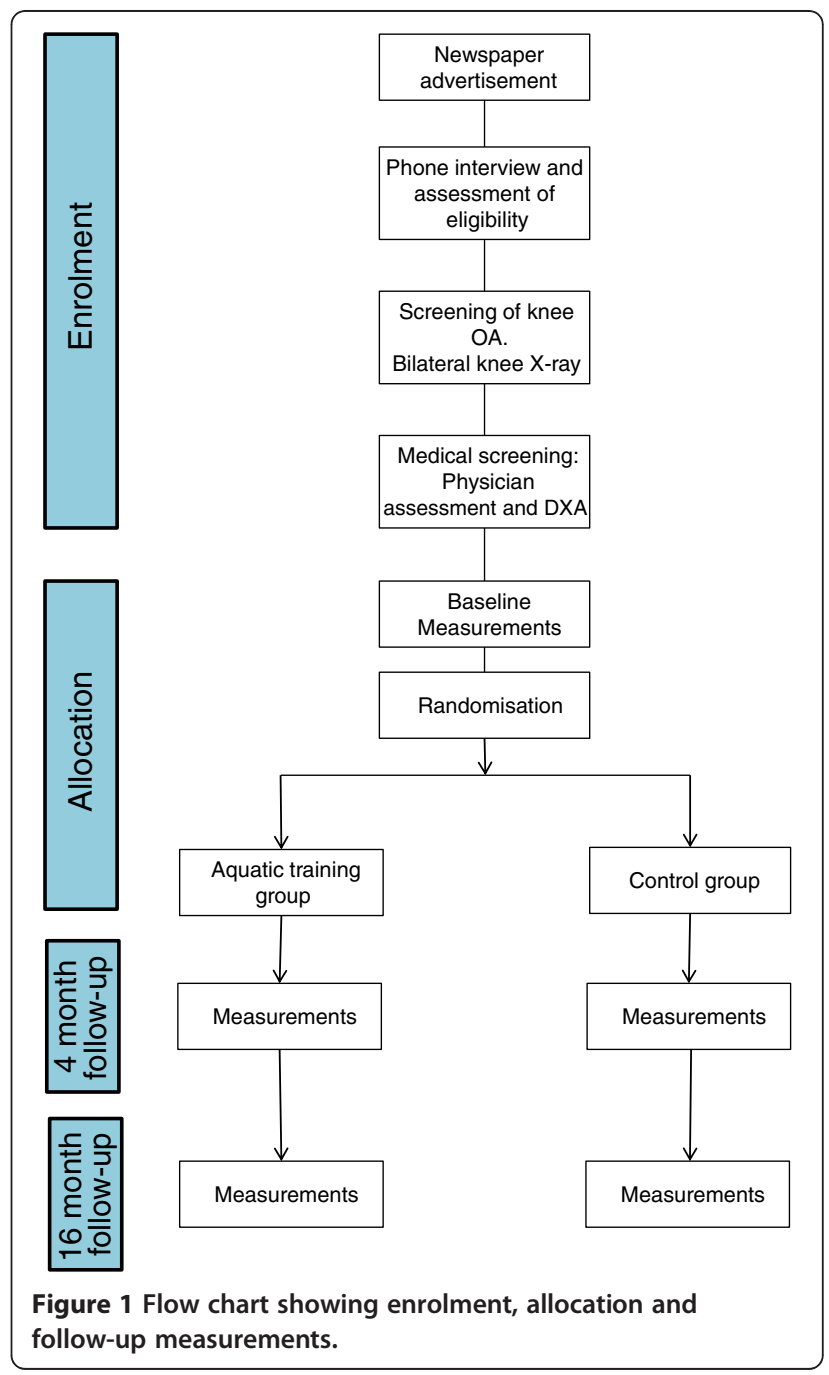


dGEMRIC and T2 variables. Based on data from Roos et al. [54] and Tiderius et al. [55] it is estimated that 30 subjects are needed, at $80 \%$ power, to detect a mean \pm SD difference of $40 \pm 40 \mathrm{msec}$ in the dGEMRIC between groups [54]. It is estimated that dropout rate will be about $20 \%$ at the 16 months follow up, consequently at least 70 subjects will need to be recruited.

\section{Randomisation and blinding}

The subjects will be randomly allocated into either of the two arms of the study by an external statistician blinded for the intervention and study participants and will only be provided with a randomisation number for each participant and severity of $\mathrm{OA}$ in knee according to $\mathrm{x}$-ray classification. A computer generated block randomisation of size of ten, stratified according to Kellgren-Lawrence grading 1 and 2, will be used to ensure equal distribution of severity of OA within each group and equal group size.

As with all exercise intervention studies blinding of the subject from the intervention is not possible. Researchers (BW, MM, AH) will be blinded to the allocation of groups as well as blinded from the interventions and measurement except for pQCT (MM) and DXA (BW) measurements. Due to practical limitations the physical therapists providing the intervention will also be performing the physical performance measurements. All statistical analyses will be completed by a statistician (HK), who is blinded to the participants and measurements.

\section{Primary outcomes}

This research project will have two primary outcome measures. Delayed gadolinium-enhance magnetic resonance imaging of cartilage (dGEMRIC), sensitive to the distribution of GAG, will be used to evaluate the biochemical composition of cartilage. Arrangement of collagen and hydration state of the cartilage will be measured using T2 relaxation time mapping. Furthermore, knee cartilage morphology as a regional cartilage thickness will be analysed from the weight bearing area of tibiofemoral and patellofemoral cartilages. The dGEMRIC method has been validated in several in vitro studies [60-62] and it had been applied in several in vivo studies [43,52,63-71]. Also, T2 relaxation time method has been histologically validated in vitro [72], and it has been applied in several human studies to assess chondral repair [69,73-76].

\section{MRI protocols}

Prior to imaging, the subject will be advised to restrain from any strenuous physical activity during the 48 hours prior to the measurements to minimise possible transient changes in knee cartilage volume and composition. Subjects will be imaged at the same time of the day to avoid possible diurnal variation at the follow-up measurements. The participants will be imaged lying supine with knee to be imaged in slight flexion, stabilized in a leg holder and a custom made inflatable cushion. The cushion has been specifically designed to stabilize the patella without causing any compression of the patellofemoral joint. The imaging session will last in total 3 hours and will include initially a standard clinical MRI series and T2 relaxation time followed by a dGEMRIC series.

T2 mapping will be performed using a sagittal multislice multi-echo fast spin echo sequence (field of view (FOV) $140 \mathrm{~mm}$, acquisition matrix $256 \times 256$, repetition time (TR) $2090 \mathrm{~ms}$, eight echo times (TE) between 13 and $104 \mathrm{~ms}$, echo train length (ETL) 8, slice thickness $3 \mathrm{~mm}$ ). The slices will be positioned perpendicular to a line tangential to the posterior femoral condyles in the axial scout view. Two slices, each covering the central region of the medial and lateral condyles, will be analysed.

For the dGEMRIC series, immediately after the clinical and T2 imaging a double dose of Gd-DTPA ${ }^{2-}$ (Magnevist, Schering, Berlin) will be administered intravenously i.e., $0.4 \mathrm{ml} / \mathrm{kg}(0.2 \mathrm{mM} / \mathrm{kg})$. At baseline, post intervention and 16 month follow up the amount of contrast administered will be corrected for body weight. It is felt this is appropriate because of the expected changes in body composition as a result of the intensive exercise intervention. In order to enhance the delivery of contrast agent into the knee cartilage, following administration of Gd-DTPA ${ }^{2-}$ the subject will be instructed to perform 5 minutes of flexionextension exercises in a sitting position without resistance, 5 minutes of walking on a flat surface and 10 gentle deep squats. Exactly ninety minutes after the injection, T1 mapping in the presence of Gd-DTPA ${ }^{2-}$ (dGEMRIC) will be performed in the sagittal plane using a single slice inversion recovery fast-spin echo sequence $(\mathrm{FOV}=14 \mathrm{~cm}$, matrix $256 \times 256, \mathrm{TR}=1800 \mathrm{~ms}, \mathrm{TE}=13 \mathrm{~ms}$, six inversion times (TI) between 50 and $1600 \mathrm{~ms}$, slice thickness $3 \mathrm{~mm}$ ). The slice positioning will be copied from the T2 relaxation time mapping sequence, and the number of the slices in the correct orientation is reduced to one. The remaining slice is then positioned at the centre of the medial and lateral condyles as viewed on the axial scout image. The subject will be positioned into an identical position as for the first MRI imaging. For both the MRI images and pQCT measurements the knee with highest degree OA, as measured by the radiographic Kellgren-Lawrence scale, will be imaged. In the cases were both knee have identical KL score the right knee will be imaged.

\section{Segmentation}

Weight bearing cartilage regions of interest (ROIs) from single sagittal slices at the centre of the medial and 
lateral tibial and femoral condyles will be segmented using a semi-automated in-house MATLAB application (Mathworks, Inc. Natick, MA, USA). dGEMRIC indices will be corrected for BMI [77]. In this research team the in vivo precision of dGEMRIC for full thickness cartilage in different ROIs ranges from 5\% to 7\% [78]. The interobserver precision of $\mathrm{T} 2$ in different locations is on average 5\% [79]. For quality assurance purposes, a set of phantom samples containing certain concentrations of agarose and nickel nitrate to modulate their T1 and T2 relaxation times will be imaged following the study protocol prior to baseline and follow-up measurement sessions to assess possible drift.

\section{Secondary outcomes}

\section{Properties of bone and body composition}

Peripheral quantitative computed tomography (pQCT) The bone properties of the distal radius and mid and distal tibia will be measured using a pQCT device (XCT2000; Stratec Medizintechnik, Pforzhem, Germany). A 2-mm-thick single tomographic slice with pixel size $0.59 \mathrm{~mm}$ in plane resolution will be taken at $5 \%$ and $55 \%$ of the length of the tibia proximal to the distal end of the tibia. Lower leg length is defined as the distance between the medial condyle of tibia and medial malleolus. Selection of lower limb to be imaged will be based on the same principles as the MRI scan. The forearm slice will be taken at $4 \%$ of ulna length proximal to the distal endplate of ulna. Length of ulna is defined as the distance between olecranon process and the midline of lateral aspect of distal ulna. In all cases right upper limb will be scanned except when subjects had suffered from fracture of either right ulna or radius. The analysis of the pQCT images will be performed with the density distribution plug-in [80] of the BoneJ (http://bonej.org/ densitydistribution) [81] ImageJ (http://rsbweb.nih.gov/ij/ download.html) plug-in. Compressive bone strength index $\left(\mathrm{BSI}_{\mathrm{d}}, \mathrm{g}^{2} / \mathrm{cm}^{4}\right)$, bone mineral content (BMC), total and trabecular density (ToD and $\operatorname{TrD}, \mathrm{mg} / \mathrm{cm}^{3}$ ) and total and trabecular area (ToA and TrA, $\mathrm{mm}^{2}$ ) will be analysed from the shaft slices. The pQCT device is calibrated daily using a standard phantom provided by the manufacturer and coefficient of variation (CV) for these protocols in our laboratory has been measured to range between 1.5-3.4\% for the reported variables [82].

\section{Dual-energy X-ray absorptiometry (DXA)}

DXA (Lunar Prodigy; GE Lunar Healthcare, Madison, WI, USA) will be used to assess body composition and bone traits. Body composition analyses will be carried out using enCORE software (ENcore 2011, version 13.60.033). Using manufacturers software and protocols total body fat and lean body mass will be measured. In vivo precision of these measurements has been reported to be CV 1.3$2,2 \%$ [83]. Both proximal femur and Lumbar spine (L2-4) areal bone mineral density (aBMD, g/cm ${ }^{2}$ ) and bone mineral content (BMC, g) will be scanned. Cross sectional geometry of the femoral neck will be analysed using advanced hip structure analysis (AHA) as per manufacturer's software. This will include femoral neck hip axis length (HAL, mm), cross sectional area (CSA, $\mathrm{mm}^{2}$ ), cross sectional moment of inertia (CSMI, $\mathrm{mm}^{4}$ ) and femoral neck strength index (FSI, $\mathrm{mm}^{3}$ ) [84-86]. In vivo repeatability, $\mathrm{CV}$, of these methods has been reported as $2.3 \%$ for CSA [87].

\section{Questionnaires}

Health status General health and habitual physical activity at baseline will be assessed by a questionnaire devised by the research group. This health questionnaire addresses medical conditions, current medications, years of menopausal hormone therapy, history of fractures and current leisure time physical activity. Throughout the entire follow up period all subjects will be asked to report their daily amount of analgesia taken to manage their knee pain. Space will be provided in the physical activity diary for ease of recording.

\section{Impact of osteoarthritis of the knee}

Self-assessed impact of osteoarthritis on functioning will be measured using two questionnaires, the Western Ontario and McMaster Universities Osteoarthritis Index (WOMAC) [88] and the knee injury and osteoarthritis outcome score (KOOS) [89]. The visual analogue version (VAS) of the WOMAC (0-100 mm) will be used with a range of scores of $0-2400$. This questionnaire has 24 questions and is divided into three domains; pain (score ranging from 0-500), stiffness (0-200) and function (0-1700). A higher score indicates more disability. The internal consistence (Cronbach's alpha) for the VAS version is $0.7-0.91$ and test-retest (ICC) coefficient is 0.95 for pain, 0.90 for stiffness and 0.92 for function ([90]). A likert version of the KOOS will be used with each response being scored $0-4$. The questionnaire has 5 domains: pain (9 questions), other symptoms (7 questions), activities of daily living (16 questions), sport and recreation (5 questions) and knee related quality of life (4 questions). Score for global and domains scores are transformed into a score $0-100$ with a score of 0 indicating extreme knee problems and 100 no knee problems. The internal consistency for the KOOS is 0.86-0.96 and test-rest (ICC) is (0.67-0.95) [91]. Reliability of the Finnish language version of both WOMAC and KOOS has been shown to be similar to that of the English language version [92]. 


\section{Quality of life}

Self-assessed quality of life will be measured using the RAND-36-Item short form healthy survey instrument [93] this questionnaire is identical in wording to the short form 36 questionnaire (SF-36) but summation of final scores is different. It contains 8 domains: physical functioning (10 items), role limitations due to physical health problems ( 4 items), role limitations due to emotional problems (3 items), energy/fatigue (4 items), emotional well-being (5 items), social functioning (2 items), pain (2 items), and general health (5 items). Global and individual domains will be re-scored and given values of 0-100 with higher scores indicating a more favourable health state. The scores will also be divided into two summary measure: the physical component summary score (PCS) and the mental component summary score (MCS). The dimensions physical functioning, role limitation due to physical health problems, body pain and general health form the PCS and mental health, energy/ fatigue, social functioning and role limitations due to emotional problems form the MCS. In a Finnish standardization population sample aged 18-79 years the homogeneity, i.e., the mean of the item intercorrelations of the Scale, was 0.63 and Cronbach alpha 0.94 [94].

\section{Physical performance measures}

Muscle strength Maximal isometric knee flexion and extension strength of both legs, as well as grip strength of dominant hand, will be measured using an adjustable dynamometer chair (Good strength; Metitur Ltd, Jyväskylä Finland). The best result from 3 contractions will be used and recorded in newtons $(\mathrm{N})$. In our laboratory, the precision of the test is $6 \%$ for knee extension and 9\% for knee flexion [95].

\section{Muscle power}

Single leg extension power will be measured using Nottingham power rig (University of Nottingham Medical School, Nottingham, UK) which has been tested for reliability and has a test retest co-efficient of variation ( $\mathrm{CV}$ of 9.4\%) [96] and in our laboratory the $\mathrm{CV}$ is $8 \%$ [97].

In addition lower limb power function will be determined by a maximal counter movement jump (CMJ) measured using a custom made force plate (University of Jyväskylä, Finland). This test is a measure of neuromuscular function. Jumping force, vertical ground reaction forces, power, impulse and jump height will be calculated. Data is collected at a sampling frequency of $500 \mathrm{~Hz}$ [98].

\section{Aerobic fitness}

Maximal aerobic power $\mathrm{VO}_{2}$ max will be estimated using the UKK $2 \mathrm{~km}$ walk test (UKK Institute, Tampere, Finland). This test requires the subject to walk $2 \mathrm{~km}$ as quickly as possible with a target of $80 \%$ maximal heart rate [99]. $\mathrm{VO}_{2} \max$ is estimated using walking time, body mass index (BMI), age and heart rate at end of test. The heart rate will be measured by a portable heart-rate monitor (Polar F6, Polar Electro Ltd, Kempele, Finland). It is a feasible test for estimating V02 max [100] and sensitive to changes [101]. Its validity has also been tested with correlation coefficient of 0.69-0.77 [102].

\section{Static balance}

Static balance ability will be assessed using a force platform device (Goodbalance, Metitur Ltd, Jyväskylä Finland) which is validated and reliable method measuring body sway in different standing positions [103,104]. Balance will be measured in feet side-by-side eyes open and eyes closed and single leg stance [105].

\section{Agility}

Agility will be assessed with a standardised figure-of -eight running test consisting of two laps around two cones placed 10 meters apart in a figure of eight [106-108]. Time (in seconds) taken to complete the task will be measured using a photocell. This test has shown to be effective at detecting decreased motor performance (area under curve 0.86) additionally it has been shown to be a very sensitive (73.5\%) and specific (86.1\%) tool for measuring agility [109].

\section{Gait}

Spatial and temporal parameters of gait will be measured using the GAITRite ${ }^{\circledR}$ walkway (CIR systems, inc. Clifton, NJ 070872) [110]. This consists of a $577 \mathrm{~cm}$ long and $88.5 \mathrm{~cm}$ wide matt with 13,824 sensors placed on $1.27 \mathrm{~cm}$ in a grid. The collection frequency of the matt is $80 \mathrm{~Hz}$. The data is transferred by lead to a computer and is analysed using GAITRite 3.6b software. This technique has been validated with different populations $[111,112]$ and found to be a reliable [112,113] instrument to measure spatial and temporal parameters of gait.

\section{Daily physical activity}

During both the intervention period (0-4 months) and the follow up period (5-16 months) daily physical activity of every subject (excluding pool training) will be recorded using a leisure time physical activity diary. The diary is completed daily and each activity, duration and intensity ( $1=$ low, $2=$ moderate or $3=$ hard $)$ is recorded. From this data MET-hours per week will be calculated $[114,115]$. In addition, during the intervention period 
each subjects' daily activity will be measured for 3 days using a heart rate monitor (F6 Polar, Polar Oy, Finland), accelerometers (Hookie AM 20, Traxmeet, Finland) and hourly physical activity diaries.

\section{Intervention}

Those subjects randomised into the intervention group will participate in 1 hour of aquatic resistance training, three times a week for 4 months, totally 48 training sessions. The intervention will be completed in small groups of 6-8 subjects in a pool heated to 32 degrees with depths $1.3-1.5 \mathrm{~m}$. Aquatic steps will be used to ensure that all subjects will complete the standing exercises at a depth level approximately to their xiphoid bone $\pm 5 \mathrm{~cm}$ ensuring weight bearing on the supporting leg of $25-50 \%$ of own body weight [41].

Each training session will last approximately 1 hour. The session will consist of three distinct parts; the warmup (15 minutes), lower limb strengthening program (35 minutes) and cool down (10 minutes), a full description of exercises can be found from Table 1 and Figures 2, 3, 4, 5, 6. Warm up and cool down was planned by a physiotherapist with over 10 years of aquatic therapy experience with patients suffering from musculoskeletal problems (BW), the same therapist will ensure that quality of movement and intensity of the intervention is maintained throughout the training by reviewing the heart rate and perceived exertion by BORG 6-20 scale [116] which are collected after

Table 1 Description of exercises included in the intervention

\begin{tabular}{|c|c|c|}
\hline Warm-up (10-15 minutes) & Strength training (35 minutes) & $\begin{array}{l}\text { Cool down } \\
\text { (10 minutes) }\end{array}$ \\
\hline 1. Standing hip flexion/extension & $\begin{array}{l}\text { 1. Standing hip flexion/extension (Figure 3): Standing side on to wall } \\
\text { and stand on leg furthest away from wall. Swing leg nearest wall } \\
\text { forwards and backwards as fast as possible using full range of motion. } \\
\text { Keep knee of moving leg in full extension and ankle in dorsiflexion. } \\
\text { Maintain spinal neutral at all times. }\end{array}$ & $\begin{array}{l}3-5 \text { minutes of } \\
\text { walking and } \\
\text { supported cycling } \\
\text { against wall }\end{array}$ \\
\hline 2. Standing hip abduction/Abduction & $\begin{array}{l}\text { 2. Hip adduction/abduction (Figure 2): Stand on right leg with knee } \\
\text { fully extended. Keeping knee straight and ankle in dorsiflexion swing } \\
\text { left leg from side to side as fast as possible using full range of motion. } \\
\text { Left leg crosses over in front of right leg. Particular attention is paid to } \\
\text { maintaining a neutral pelvic and spinal position. }\end{array}$ & $\begin{array}{l}\text { Stretches, } 30 \text { seconds } \\
\text { stretch for each side. }\end{array}$ \\
\hline 3. Seated bilateral knee flexion/extension. & $\begin{array}{l}\text { 3. Seated knee flexion/extension (Figure 5): Sitting on chair keeping } \\
\text { back of legs fixed against seat, alternately flex and extend both knees } \\
\text { as fast as possible using full range of motion. }\end{array}$ & $\begin{array}{l}\text { 1. Hip flexors } \\
\text { (Iliopsoas) }\end{array}$ \\
\hline $\begin{array}{l}\text { 4. Calf raises on edge of step (weeks 1-8 double } \\
\text { leg, weeks } 9-16 \text { single leg) }\end{array}$ & $\begin{array}{l}\text { 4. Standing knee flexion/extension (Figure 4): Standing side on to wall } \\
\text { and transfer weight on to leg furthest away from wall. Lift leg nearest } \\
\text { wall straight up in front stopping just before any stretch sensation is } \\
\text { felt in the posterior aspect of thigh. Keeping thigh still, flex and extend } \\
\text { knee as fast as possible using full range of motion. }\end{array}$ & 2. Gluteus maximus \\
\hline $\begin{array}{l}\text { 5. Balance beam (EWAC, Netherlands) walking } \\
\text { forwards and backwards (weeks 1-6 without arms, } \\
\text { weeks 6-12 carry tray with ball on, 13-16 same } \\
\text { eyes closed) }\end{array}$ & $\begin{array}{l}\text { 5. Kickback (reverse lunge) (Figure 6): Standing on edge of step board } \\
\text { so that moving leg can be swung down next to it. Starting position is } \\
\text { with supporting leg in full extend and other hip and knee is in } \\
\text { flexion up near wall. Leg is explosively straightened down towards } \\
\text { bottom of pool and then kicked backwards with leg straight as far as } \\
\text { possible. During this movement supporting leg is flexed but plantar } \\
\text { aspect of foot is kept firmly pressed against step. }\end{array}$ & 3. Quadriceps \\
\hline $\begin{array}{l}\text { 6. Standing abdominals (either pushing and pull } \\
\text { frisbee, trunk rotation with frisbee or rowing with } \\
\text { aquatic rolling pin), weeks 1-8 double leg stance, } \\
\text { week } 9-16 \text { single leg). }\end{array}$ & & 4. Hamstrings \\
\hline $\begin{array}{l}\text { 7. Abdominal with feet in frisbee against wall } \\
\text { (figure of } 8 \text {, circles } 30 \text { second each direction) }\end{array}$ & & 5. Iliotibial band \\
\hline $\begin{array}{l}\text { 8. Hurdles (EWAC Netherlands), weeks } 1-6 \\
\text { stepping over hurdles, weeks } 6-12 \text { double leg } \\
\text { jumps forwards and backwards over } 30 \mathrm{~cm} \text { hurdle, } \\
13-16 \text { single leg jumps forwards over } 30 \mathrm{~cm} \text { high } \\
\text { hurdle) }\end{array}$ & & 6. Adductors \\
\hline $\begin{array}{l}\text { 9. Weeks 1-6 scissor jumps, weeks } 6-12 \text { jumping } \\
\text { over } 30 \mathrm{~cm} \text { hurdle sideways, weeks, } 13-16 \text { single } \\
\text { leg sideways jumping over } 30 \mathrm{~cm} \text { hurdle. }\end{array}$ & & 7. Gastrocnemius \\
\hline $\begin{array}{l}\text { 10. Dynamic balance } 1 / 2 \text { of the group jog/run } \\
\text { around other } 1 / 2 \text { of group who are trying to } \\
\text { maintain balance. }\end{array}$ & & \\
\hline
\end{tabular}




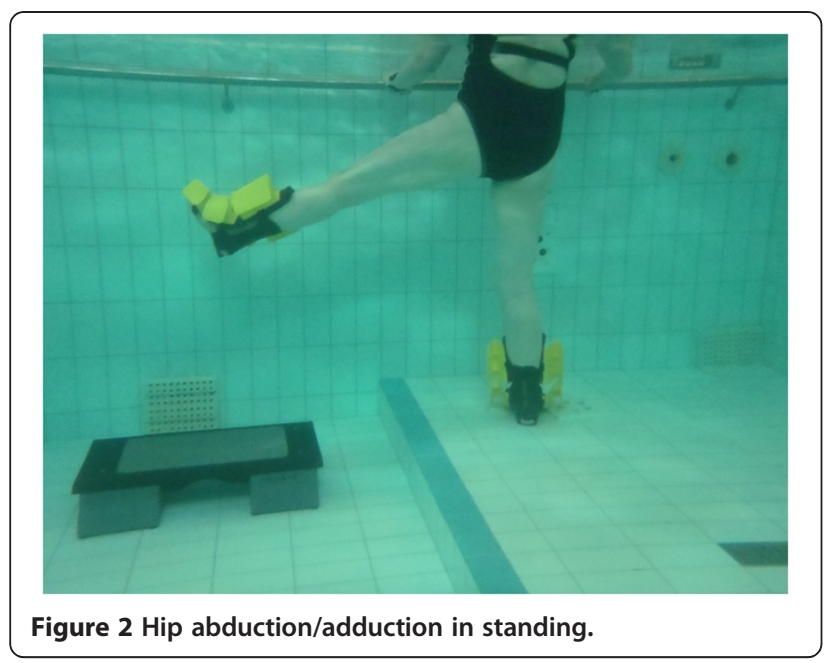

every training session immediately after the main set before the cool down. All sessions will be supervised by 2 experienced physiotherapists, who had been trained to instruct these aquatic programmes and accredited for lifesaving before the trial began.

The warm-up consists of 10 different movements to increase active ROM of all joints and enhance neuromuscular activation. Each movement will be completed for 1 minute (30 seconds per leg when alternating leg) with a 15 second rest period. Order of movements will be altered for each session randomly to maximise neuromuscular stimulation and prevent staleness as well as to maintain subjects' interest.

The strength training section consists of 5 exercises which have been thoroughly researched for both their effect on muscle activation $[117,118]$ and effect on muscle strength and physical functioning [119-121]. Focus will be on performing each movement as fast as possible through full ROM. During all standing exercises emphasis will be made on maintaining the lumbar spine in

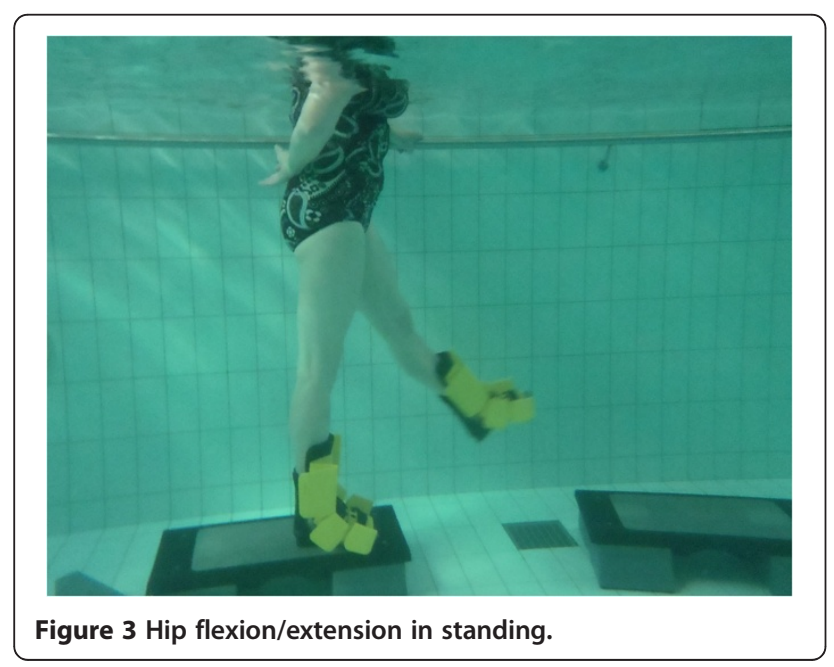

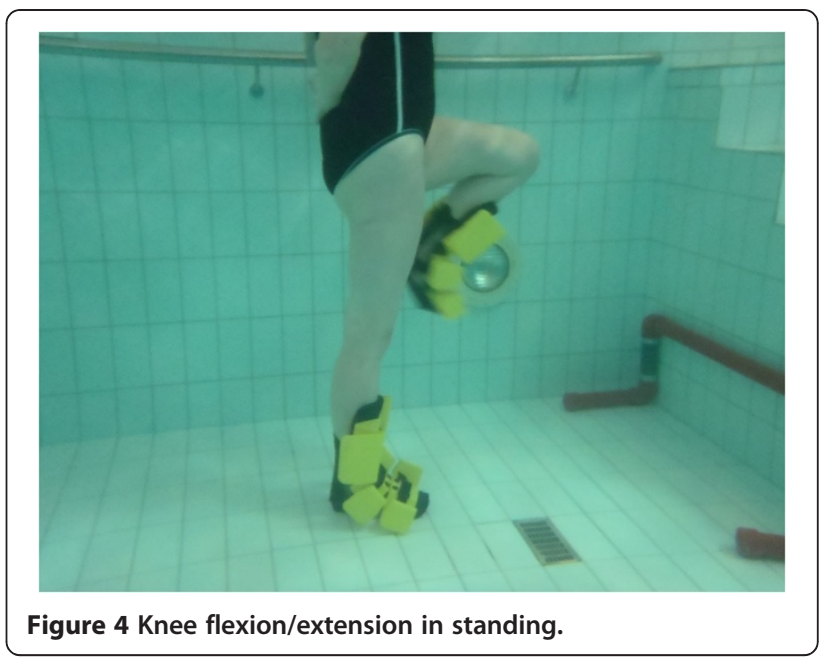

a neutral position thus avoiding excessive loading on the spine and to encourage activation of trunk muscles during exercises. The progression of the exercise program will be ensured by using resistance boots of different sizes and by varying the duration of sets. Table 2 shows the different durations of each set and targeted amount of repetitions per set for each stage of the intervention. Each leg will be trained before resting e.g. 45 seconds left leg, 45 seconds right leg and 30 second rest.

Weeks $1-2$ is an introductory period to allow subjects to become familiar with the movements with sets of 45 seconds duration per leg per set with no resistance i.e. barefoot. Weeks 3-5 will consist of alternate trainings of 30 or 45 seconds with small fins (THERABAND PRODUCTS, The Hygienic Corporation, Akron, OH 44310 USA). Weeks $6-8$ will be 3 week period with 45 seconds of work alternating sessions with small aquafins and large resistance boots (Hydro-Tone hydro-boots, Hydro-Tone Fitness Systems, Inc. Orange, CA 92865-2760, USA). Weeks 9-11 and 13-16 will consist of alternate trainings with

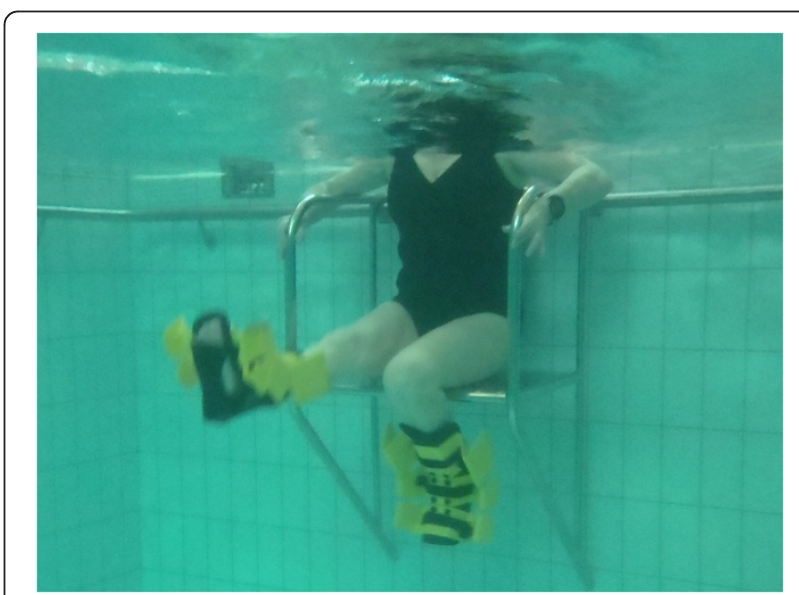

Figure 5 Knee flexion/extension in sitting. 


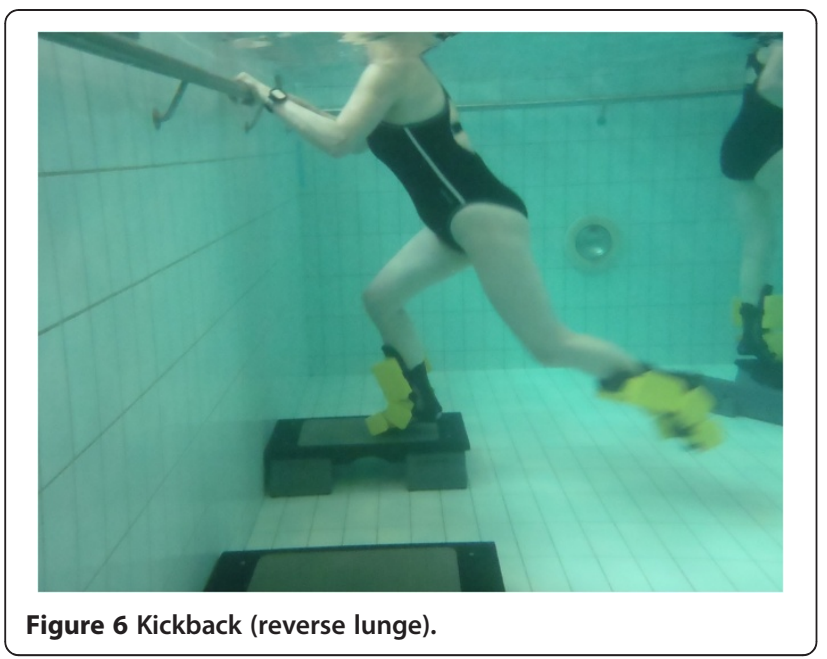

work of 30 and 45 seconds with large boots. Week 12 will consist of one session barefooted, one with small fins and one with large boots, work duration will be 45 seconds per set. The frontal area of aquafin resistance fins is $0.0181 \mathrm{~m}^{2}$ and that of the large resistance boots $0.075 \mathrm{~m}^{2}$. In a previous study the drag experienced during seated aquatic knee flexion/extension exercises in healthy women was triple with the large boots compared to the barefoot condition. Additionally, a significant increase in EMG activity was seen with the large boots compared to no boots $[117,122]$.

Intensity of training of every session will be monitored using polar heart rate monitors (F6 or RCX5, Polar Oy, Finland) and perceived rate of exertion (BORG 6-20) [116]. Target training zone will be $60-80 \%$ of maximum heart rate according to the Karvonen formula e.g. $60 \%$ training limit $=(220-$ age $) \times 0.6$ and $80 \%$ training limit $=$ (220 - age) x 0.8 .

Blood lactate levels will also be measured so as to obtain quantitative measures of training intensity and to ensure all training groups have trained at similar intensities. Samples will be taken during week 12, before training after 15 minutes of rest and 3 minutes after cessation of main strength training session. These will be recorded for each different intensity level of training (barefoot, small and large resistance boots, 45 seconds work per leg). Fingertip blood samples will be taken using safety lancet, normal $21 \mathrm{G}$ with penetration depth $1.8 \mathrm{~mm}$ (Sarstedt AG \& co, Germany) and collected into $20 \mu \mathrm{L}$ capillary tubes which are placed in 1-mL hemolyzing solution. Care will be taken to clean skin to avoid contamination from chlorinated pool water. Samples will be analysed using an automatic system (EKF diagnostic, Biosen, Germany) after training.

\section{Control group}

The control group will be asked to maintain normal physical activity during the intervention period. They will be offered two sham contact sessions consisting of 1 hour of light stretching and relaxation during the 4 month period.

\section{Follow up period}

After the post intervention measurements all participants will be advised to continue spontaneous physical activity, no other specific instruction will be given to the subject.

\section{Ethical considerations}

The study was given ethical consent on $30^{\text {th }}$ November 2011 Dnro 19U/2011 from the Ethics Committee of the Central Finland Health Care District. Written informed consent will be obtained from all subjects before their participation in the study. All subjects included have the right to withdraw from the study whenever without needing to provide a reason for withdrawal. The study will be conducted according to good clinical and scientific guidelines and the declaration of Helsinki (2000).

\section{Assessment of side effects}

Adverse effects or health problems attributable to the testing protocol or interventions exercise protocol will be documented and reported. Following each individual measurement and training session self-reported knee pain will be assessed using a visual analogue scale (VAS 0$100 \mathrm{~mm}$ ) along with any other physical symptoms such as pain elsewhere than knee, stiffness and general fatigue. All subjects will have medical insurance and have access to

Table 2 Intensity and progression of each program for phase's I-IV of aquatic exercises program

\begin{tabular}{|c|c|c|c|c|c|c|c|c|}
\hline Weeks & $\begin{array}{l}\text { Resistance } \\
\text { type }\end{array}$ & Sets & $\begin{array}{c}\text { Repetitions per } \\
\text { set }\end{array}$ & $\begin{array}{l}\text { Time } \\
(\mathrm{sec})\end{array}$ & $\begin{array}{l}\text { Recovery } \\
\text { (sec) }\end{array}$ & $\begin{array}{l}\text { Target } \\
\text { PRE* }^{*}\end{array}$ & $\begin{array}{l}\text { Total time } \\
\text { (mins) }\end{array}$ & $\begin{array}{l}\text { Total No. } \\
\text { reps }\end{array}$ \\
\hline $1-2$ & Barefoot & 3 & $25-30$ & 45 & 30 & $14-15$ & 30 & $750-900$ \\
\hline \multirow[t]{2}{*}{ 3-5 (alternating) } & Small & 3 & $20-25$ & 45 & 30 & $15-16$ & 30 & $600-750$ \\
\hline & Small & 3 & 12 to 15 & 30 & 45 & $16-17$ & 26 & $288-360$ \\
\hline 6-8 and 12 & Small/Large & 3 & $14-20$ & 45 & 30 & $16-17$ & 30 & $420-600$ \\
\hline \multirow{2}{*}{$\begin{array}{l}\text { 9-11 and 13-16 } \\
\text { (alternating) }\end{array}$} & Large & 3 & $14-20$ & 45 & 30 & $16-18$ & 30 & $420-600$ \\
\hline & Large & 3 & 12 to 15 & 30 & 45 & $16-18$ & 26 & $288-360$ \\
\hline
\end{tabular}

*PRE = perceived rate of exertion (BORG 6-20). 
the attending medical physician free of charge throughout the 4 month intervention and 12 month follow up period.

\section{Statistical analysis}

All analyses will be based on both intention-to-treat and dose related principles. Statistical analyses will be performed using statistical software (Stata, release 12.1, StataCorp, College Station, Texas and SPSS Version 19, IBM Corporation).

\section{Discussion}

This paper describes the rationale and design of a randomised control trial investigating the effect a progressive aquatic resistance training program will have on patellofemoral and tibiofemoral cartilage, properties of bone and body composition and physical function in post-menopausal women with mild knee osteoarthritis.

Exercise is one of the main non-pharmaceutical treatments recommended in the management of lower limb OA [24-26,28,29]. It is presumed that training in an aquatic environment has benefits for persons suffering from lower limb OA, however exact content and intensity of optimal training remain unclear [22]. For persons with knee and/or hip OA there is strong evidence to suggest aquatic exercise can cause a small but significant reduction in pain $[30,33,34,36,38,123-127]$, improves self-assessed and measured function with a small to moderate effect size [33-36,38,123-125,127-130]. In addition, there is moderate evidence to show that aquatic exercise can cause a small but significant improvement in aerobic fitness $[33,35,127,129,131]$. Further there is limited data to suggest aquatic exercise can increase lower limb strength [33-39] and improve balance and decrease risk of falling [36,39,40]. Intensities of interventions in previously studies may not have been high enough to produce large changes in muscle strength and cardiovascular fitness but reporting of exercise programs used are in most cases incomplete. There are few studies investigating the effect of a progressive resistance program using specifically designed resistance equipment to manage symptoms associated with knee OA even though there is accumulating evidence to suggest it can be effective in improving neuromuscular function [117,118,120-122]. Also, there is some evidence to suggest water based exercise can either maintain [132] or slightly improve the properties of bone as measured with DXA [133]. However these are of low quality evidence and further research is required to validate the findings.

Both dGEMRIC [63,134] and T2 relaxation MRI $[7,72,135]$ can distinguish between normal and OA cartilage. These techniques have been shown to be sensitive enough to demonstrate acute changes in human cartilage dGEMRIC [42,67] and T2-relaxation times [42,136]. These methods are therefore suitable for use in our study, and it is known that correct biomechanical loading of cartilage is important in maintaining cartilage health whereas obesity and trauma are risk factors for the development of OA [1]. Although there is evidence to show that biochemical characteristics of cartilage can be negatively affected with changes after periods of joint immobilization [137,138] and non-weight bearing [136]. No evidence exists to show the impact of an intensive non-impact exercise on cartilage.

As far as we know there have been no publications investigating the effect of aquatic exercise on cartilage and properties of bone in persons with knee OA. The aim of this study is to use repetitive aquatic resistance program with high intensity and repetition to discover what effects non-impact training has on knee cartilage, properties of bone and physical function. The information gained will help improve our understanding of the effects of exercise on the biochemical properties of cartilage and improve prescription of aquatic exercises in the management of OA.

\section{Abbreviations \\ OA: Osteoarthritis; ROM: Range of Motion; PQCT: Peripheral quantitative computed tomography; DXA: Dual-energy X-ray absorption; WOMAC: Western Ontario and McMaster Universities Osteoarthritis Index; KOOS: Knees injury and Osteoarthritis Outcome Score; CV: Coefficient of Variation; VAS: Visual Analogue Scale; RPE: Rate of Perceived Exertion; MRI: Magnetic Resonance Imaging; dGEMRIC: Delayed Gadolinium-Enhance Magnetic Resonance Imaging of Cartilage; FOV: Field of View; TR: Repetition Time; TE: Echo Times; ETL: Echo Train Length; GAG: Glycosaminoglycan; BMD: Bone Mineral Density; BSI: Bone Strength Index; BMC: Bone Mineral Content; ToD: Total Density; TrD: Trabecular density; ToA: Total Area; TrA: Trabecular Area; aBMD: Areal Bone Mineral Density; BMC: Bone Mineral Content; AHA: Advance Hip structure Analysis; HAL: Hip Axis Length; CSA: Cross Sectional Area; CSMI: Cross Sectional Moment of Inertia (CSMI); FSI: Femoral neck Strength Index; BMI: Body Mass Index; CMJ: Counter Movement Jump; ECG: Echocardiogram.}

\section{Competing interests}

All authors declare that they have no competing interests.

\section{Authors' contributions}

All authors were involved in the conception of the study plan and design as well as critically revising the draft manuscript for important intellectual content. All authors approved the final version to be published. BW, MM, JM and AHeinonen drafted the manuscript.

\section{Acknowledgements}

The study has supported by funding from the Academy of Finland and the Social Insurance Institution of Finland.

\footnotetext{
Author details

${ }^{1}$ Department of Health Sciences, University of Jyväskylä, Jyväskylä, Finland. ${ }^{2}$ Rehabilitation and Pain Unit, Kymenlaakso Central Hospital, Kotka, Finland. ${ }^{3}$ Department of Diagnostic Radiology, Oulu University Hospital, Oulu, Finland. ${ }^{4}$ Department of Radiology, University of Oulu, Oulu, Finland. ${ }^{5}$ Department of Orthopaedics and Traumatology, University of Helsinki and Helsinki University Hospital, Helsinki, Finland. ${ }^{6}$ Department of Orthopaedics and Traumatology, Jyväskylä Central Hospital, Jyväskylä, Finland. ${ }^{7}$ Unit of Family Practice, Central Finland Central Hospital, Jyväskylä, Finland. ' LIKES Research Centre, Jyväskylä, Finland. ${ }^{9}$ Department of Rehabilitation Medicine, VU University Medical Center, Amsterdam, the Netherlands. ${ }^{10}$ Gerontology Research Center, University of Jyväskylä, Jyväskylä, Finland. ${ }^{11}$ Department of Physical Medicine and Rehabilitation, Central Finland Central Hospital, Jyväskylä, Finland.
} 
Received: 7 February 2013 Accepted: 27 February 2013

Published: 7 March 2013

\section{References}

1. Suri P, Morgenroth DC, Hunter DJ: Epidemiology of osteoarthritis and associated comorbidities. PM R 2012, 4(5 Suppl):S10-9.

2. Felson DT, Naimark A, Anderson J, Kazis L, Castelli W, Meenan RF: The prevalence of knee osteoarthritis in the elderly. The Framingham Osteoarthritis Study. Arthritis Rheum 1987, 30(8):914-918.

3. Dequeker J, Aerssens J, Luyten FP: Osteoarthritis and osteoporosis: clinical and research evidence of inverse relationship. Aging Clin Exp Res 2003, 15(5):426-439.

4. Dillon CF, Rasch EK, Gu Q, Hirsch R: Prevalence of knee osteoarthritis in the United States: arthritis data from the Third National Health and Nutrition Examination Survey 1991-94. J Rheumatol 2006, 33(11):2271-2279.

5. Jordan JM, Helmick CG, Renner JB, Luta G, Dragomir AD, Woodard J, Fang F, Schwartz TA, Abbate LM, Callahan LF, Kalsbeek WD, Hochberg MC: Prevalence of knee symptoms and radiographic and symptomatic knee osteoarthritis in African Americans and Caucasians: the Johnston County Osteoarthritis Project. J Rheumatol 2007, 34(1):172-180.

6. Lawrence RC, Felson DT, Helmick CG, Arnold LM, Choi H, Deyo RA, Gabriel S, Hirsch R, Hochberg MC, Hunder GG, Jordan JM, Katz JN, Kremers HM, Wolfe F, National Arthritis Data W: Estimates of the prevalence of arthritis and other rheumatic conditions in the United States. Part II. Arthritis Rheum 2008, 58(1):26-35.

7. Baum T, Joseph GB, Arulanandan A, Nardo L, Virayavanich W, CarballidoGamio J, Nevitt MC, Lynch J, McCulloch CE, Link TM: Association of magnetic resonance imaging-based knee cartilage T2 measurements and focal knee lesions with knee pain: data from the Osteoarthritis Initiative. Arthritis Care Res 2012, 64(2):248-255.

8. Scanzello CR, Goldring SR: The role of synovitis in osteoarthritis pathogenesis. Bone 2012, 51(2):249-257.

9. Vincent HK, Heywood K, Connelly J, Hurley RW: Obesity and weight loss in the treatment and prevention of osteoarthritis. PM R 2012, 4(5 Suppl): S59-67.

10. Henrotin Y, Pesesse L, Sanchez C: Subchondral bone and osteoarthritis: biological and cellular aspects. Osteoporos Int 2012, 23(Suppl 8):847-851.

11. Suri S, Walsh DA: Osteochondral alterations in osteoarthritis. Bone 2012, 51(2):204-211

12. Sofat N, Ejindu V, Kiely P: What makes osteoarthritis painful? The evidence for local and central pain processing. Rheumatology (Oxford) 2011, 50(12): 2157-2165.

13. Knoop J, Steultjens MP, van der Leeden M, van der Esch M, Thorstensson CA, Roorda LD, Lems WF, Dekker J: Proprioception in knee osteoarthritis: a narrative review. Osteoarthr Cartil 2011, 19(4):381-388.

14. Baker KR, Xu L, Zhang Y, Nevitt M, Niu J, Aliabadi P, Yu W, Felson D: Quadriceps weakness and its relationship to tibiofemoral and patellofemoral knee osteoarthritis in Chinese: the Beijing osteoarthritis study. Arthritis Rheum 2004, 50(6):1815-1821.

15. Pietrosimone BG, Hertel J, Ingersoll CD, Hart JM, Saliba SA: Voluntary quadriceps activation deficits in patients with tibiofemoral osteoarthritis: a meta-analysis. PM R 2011, 3(2):153-162. quiz 162.

16. van Dijk GM, Veenhof C, Schellevis F, Hulsmans H, Bakker JP, Arwert H, Dekker JH, Lankhorst GJ, Dekker J: Comorbidity, limitations in activities and pain in patients with osteoarthritis of the hip or knee. BMC Musculoskelet Disord 2008, 9:95. 2474-9-95.

17. van Dijk GM, Dekker J, Veenhof C, van den Ende CH, Carpa Study Group: Course of functional status and pain in osteoarthritis of the hip or knee: a systematic review of the literature. Arthritis Rheum 2006, 55(5):779-785.

18. Knoop J, van der Leeden M, van der Esch M, Thorstensson CA, Gerritsen M, Voorneman RE, Lems WF, Roorda LD, Dekker J, Steultjens MP: Association of lower muscle strength with self-reported knee instability in osteoarthritis of the knee: results from the Amsterdam Osteoarthritis cohort. Arthritis Care Res 2012, 64(1):38-45.

19. Arden NK, Crozier S, Smith H, Anderson F, Edwards C, Raphael H, Cooper C: Knee pain, knee osteoarthritis, and the risk of fracture. Arthritis Rheum 2006, 55(4):610-615.

20. Fransen M, McConnell S, HernandezMolina G, Reichenbach S: Exercise for osteoarthritis of the hip. Cochrane Database Syst Rev 2009, 3(3). http://www.thecochranelibrary.com.
21. Fransen M, McConnell S: Exercise for osteoarthritis of the knee. Cochrane Database Syst Rev 2009, 3(3). http://www.thecochranelibrary.com.

22. Bennell KL, Hinman RS: A review of the clinical evidence for exercise in osteoarthritis of the hip and knee. J Sci Med Sport 2011, 14(1):4-9.

23. Bennell KL, Hunter DJ, Hinman RS: Management of osteoarthritis of the knee. BMJ 2012, 345:e4934

24. Zhang W, Moskowitz RW, Nuki G, Abramson S, Altman RD, Arden N, BiermaZeinstra S, Brandt KD, Croft P, Doherty M, Dougados M, Hochberg M, Hunter DJ, Kwoh K, Lohmander LS, Tugwell P: OARSI recommendations for the management of hip and knee osteoarthritis, part I: critical appraisal of existing treatment guidelines and systematic review of current research evidence. Osteoarthr Cartil 2007, 15(9):981-1000.

25. Zhang W, Moskowitz RW, Nuki G, Abramson S, Altman RD, Arden N, BiermaZeinstra S, Brandt KD, Croft P, Doherty M, Dougados M, Hochberg M, Hunter DJ, Kwoh K, Lohmander LS, Tugwell P: OARSI recommendations for the management of hip and knee osteoarthritis, Part II: OARSI evidencebased, expert consensus guidelines. Osteoarthr Cartil 2008, 16(2):137-162.

26. Zhang W, Doherty M, Arden N, Bannwarth B, Bijlsma J, Gunther KP, Hauselmann HJ, Herrero-Beaumont G, Jordan K, Kaklamanis P, Leeb B, Lequesne M, Lohmander S, Mazieres B, Martin-Mola E, Pavelka K, Pendleton A, Punzi L, Swoboda B, Varatojo R, Verbruggen G, Zimmermann-Gorska I, Dougados M, EULAR Standing Committee for International Clinical Studies Including Therapeutics (ESCISIT): EULAR evidence based recommendations for the management of hip osteoarthritis: report of a task force of the EULAR Standing Committee for International Clinical Studies Including Therapeutics (ESCISIT). Ann Rheum Dis 2005, 64(5):669-681.

27. Peters MJ, Symmons DP, McCarey D, Dijkmans BA, Nicola P, Kvien TK, McInnes IB, Haentzschel H, Gonzalez-Gay MA, Provan S, Semb A, Sidiropoulos P, Kitas G, Smulders YM, Soubrier M, Szekanecz Z, Sattar N, Nurmohamed MT: EULAR evidence-based recommendations for cardiovascular risk management in patients with rheumatoid arthritis and other forms of inflammatory arthritis. Ann Rheum Dis 2010, 69(2):325-331.

28. Hochberg MC, Altman RD, April KT, Benkhalti M, Guyatt G, McGowan J, Towheed T, Welch V, Wells G, Tugwell P, American College of Rheumatology: American College of Rheumatology 2012 recommendations for the use of nonpharmacologic and pharmacologic therapies in osteoarthritis of the hand, hip, and knee. Arthritis Care Res 2012, 64(4):465-474.

29. Peter WF, Jansen MJ, Hurkmans EJ, Bloo H, Dekker J, Dilling RG, Hilberdink W, Kersten-Smit C, de Rooij M, Veenhof C, Vermeulen HM, de Vos RJ, Schoones JW, Vliet Vlieland TP, Guideline Steering Committee - Hip and Knee Osteoarthritis: Physiotherapy in hip and knee osteoarthritis: development of a practice guideline concerning initial assessment, treatment and evaluation. Acta Reumatol Port 2011, 36(3):268-281.

30. Bartels EM, Lund H, Hagen KB, Dagfinrud H, Christensen R, DanneskioldSamsoe B: Aquatic exercise for the treatment of knee and hip osteoarthritis. Cochrane Database Syst Rev 2008, 1(1). http://www.thecochranelibrary.com.

31. Batterham Sl, Heywood S, Keating JL: Systematic review and meta-analysis comparing land and aquatic exercise for people with hip or knee arthritis on function, mobility and other health outcomes. BMC Musculoskelet Disord 2011, 12:123.

32. Vincent KR, Vincent HK: Resistance exercise for knee osteoarthritis. PM R 2012, 4(5 Suppl):S45-52.

33. Foley A, Halbert J, Hewitt T, Crotty M: Does hydrotherapy improve strength and physical function in patients with osteoarthritis-a randomised controlled trial comparing a gym based and a hydrotherapy based strengthening programme. Ann Rheum Dis 2003, 62(12):1162-1167.

34. Cochrane T, Davey RC, Matthes Edwards SM: Randomised controlled trial of the cost-effectiveness of water-based therapy for lower limb osteoarthritis. Health Technol Assess 2005, 9(31):1-114.

35. Wang T, Belza B, Elaine Thompson F, Whitney JD, Bennett K: Effects of aquatic exercise on flexibility, strength and aerobic fitness in adults with osteoarthritis of the hip or knee. J Adv Nurs 2007, 57(2):141-152.

36. Hinman RS, Heywood SE, Day AR: Aquatic physical therapy for hip and knee osteoarthritis: results of a single-blind randomized controlled trial. Phys Ther 2007, 87(1):32-43.

37. Lund H, Weile U, Christensen R, Rostock B, Downey A, Bartels EM, DanneskioldSamsoe B, Bliddal H: A randomized controlled trial of aquatic 
and land-based exercise in patients with knee osteoarthritis. $J$ Rehabil Med 2008, 40(2):137-144.

38. Lim JY, Tchai E, Jang SN: Effectiveness of aquatic exercise for obese patients with knee osteoarthritis: a randomized controlled trial. PM $R$ 2010, 2(8):723-731. quiz 793.

39. Hale LA, Waters $D$, Herbison $P$ : A randomized controlled trial to investigate the effects of water-based exercise to improve falls risk and physical function in older adults with lower-extremity osteoarthritis. Arch Phys Med Rehabil 2012, 93(1):27-34.

40. Arnold CM, Faulkner RA: The effect of aquatic exercise and education on lowering fall risk in older adults with hip osteoarthritis. J Aging Phys Act 2010, 18(3):245-260.

41. Harrison RA, Hillman M, Bulstrode S: Loading of the lower limb when walking partially immersed: implications for clinical practice. Physiotherapy 1992, 78(3):164-166.

42. Nieminen MT, Nissi MJ, Mattila L, Kiviranta I: Evaluation of chondral repair using quantitative MRI. J Magn Reson Imaging 2012, 36(6):1287-1299.

43. Burstein DP, Gray MP: New MRI techniques for imaging cartilage. J Bone Joint Surg Am 2003, 85-A(2):70-77.

44. Nieminen MT, Rieppo J, Toyras J, Hakumaki JM, Silvennoinen J, Hyttinen MM, Helminen HJ, Jurvelin JS: T2 relaxation reveals spatial collagen architecture in articular cartilage: a comparative quantitative MRI and polarized light microscopic study. Magn Res Med 2001, 46(3):487-493.

45. Mosher TJ, Liu Y, Yang QX, Yao J, Smith R, Dardzinski BJ, Smith MB: Age Dependency of Cartilage Magnetic Resonance Imaging T2 Relaxation Times in Asymptomatic Women. Arthritis Rheum 2004, 50(9):2820-2828.

46. Graichen H, v. EisenhartRothe R, Vogl T, Englmeier K, Eckstein F: Quantitative Assessment of Cartilage Status in Osteoarthritis by Quantitative Magnetic Resonance Imaging: Technical Validation for Use in Analysis of Cartilage Volume and Further Morphologic Parameters. Arthritis Rheum 2004, 50(3):811-816.

47. Hunter DJ, Zhang W, Conaghan PG, Hirko K, Menashe L, Reichmann WM Losina E: Responsiveness and reliability of MRI in knee osteoarthritis: a meta-analysis of published evidence. Osteoarthr Cartil 2011, 19(5):589-605.

48. Hunter DJ, Zhang W, Conaghan PG, Hirko K, Menashe L, Li L, Reichmann WM, Losina E: Systematic review of the concurrent and predictive validity of MRI biomarkers in OA. Osteoarthr Cartil 2011, 19(5):557-588.

49. van Tiel J, Bron EE, Tiderius CJ, Bos PK, Reijman M, Klein S, Verhaar JA, Krestin GP, Weinans H, Kotek G, Oei EH: Reproducibility of 3D delayed gadolinium enhanced MRI of cartilage (dGEMRIC) of the knee at 3.0 T in patients with early stage osteoarthritis. Eur Radiol 2013, 23(2):496-504.

50. Kiviranta I, Tammi M, Jurvelin J, Saamanen AM, Helminen HJ: Moderate running exercise augments glycosaminoglycans and thickness of articular cartilage in the knee joint of young beagle dogs. J Orthop Res 1988, 6(2):188-195

51. Saamanen AM, Tammi M, Kiviranta I, Jurvelin J, Helminen HJ: Levels of chondroitin-6-sulfate and nonaggregating proteoglycans at articular cartilage contact sites in the knees of young dogs subjected to moderate running exercise. Arthritis Rheum 1989, 32(10):1282-1292.

52. Tiderius CJ, Svensson J, Leander P, Ola T, Dahlberg L: dGEMRIC (delayed gadolinium-enhanced MRI of cartilage) indicates adaptive capacity of human knee cartilage. Scand J Med Sci Sports 2004, 14(5):335.

53. Teichtahl AJ, Wluka AE, Forbes A, Wang Y, English DR, Giles GG, Cicuttini FM: Longitudinal Effect of Vigorous Physical Activity on Patella Cartilage Morphology in People Without Clinical Knee Disease. Arthritis Rheum 2009, 61(8):1095-1102.

54. Roos EMPT, Dahlberg L: Positive Effects of Moderate Exercise on Glycosaminoglycan Content in Knee Cartilage: A Four-Month, Randomized, Controlled Trial in Patients at Risk of Osteoarthritis. Arthritis Rheum 2005, 52(11):3507-3514.

55. Cotofana, RingDimitriou, Hudelmaier, Himmer, Wirth, Sanger, Eckstein: Effects of Exercise Intervention on Knee Morphology in Middle-Aged Women: A Longitudinal Analysis Using Magnetic Resonance Imaging. Cells Tissues Organs 2010, 192(1):64-72.

56. Kellgren JH, Lawrence JS: Radiological assessment of osteo-arthrosis. Ann Rheum Dis 1957, 16(4):494-502.

57. Kanis JA: Assessment of fracture risk and its application to screening for postmenopausal osteoporosis: synopsis of a WHO report. WHO Study Group. Osteoporos Int 1994, 4(6):368-381.
58. Kanis JA: An update on the diagnosis of osteoporosis. Curr Rheumatol Rep 2000, 2(1):62-66

59. Kanis JA, McCloskey EV, Johansson H, Oden A, Melton LJ 3rd, Khaltaev N: A reference standard for the description of osteoporosis. Bone 2008, 42(3): 467-475.

60. Bashir A, Gray ML, Hartke J, Burstein D: Nondestructive imaging of human cartilage glycosaminoglycan concentration by MRI. Magn Res Med 1999, 41(5):857-865

61. Allen RG, Burstein D, Gray ML: Monitoring glycosaminoglycan replenishment in cartilage explants with gadolinium-enhanced magnetic resonance imaging. J Orthop Res 1999, 17(3):430-436.

62. Nieminen MT, Rieppo J, Silvennoinen J, Toyras J, Hakumaki JM, Hyttinen MM, Helminen HJ, Jurvelin JS: Spatial assessment of articular cartilage proteoglycans with Gd-DTPA-enhanced T1 imaging. Magn Res Med 2002, 48(4):640-648

63. Bashir A, Gray ML, Boutin RD, Burstein D: Glycosaminoglycan in articular cartilage: in vivo assessment with delayed Gd(DTPA)(2-)-enhanced MR imaging. Radiology 1997, 205(2):551-558.

64. Tiderius CJ, Olsson LE, De Verdier H, Leander P, Ekberg O, Dahlberg L: GdDTPA2-enhanced MRI of femoral knee cartilage: A dose-response study in healthy volunteers. Magn Res Med 2001, 46(6):1067-1071.

65. Tiderius CJ, Olsson LE, Leander P, Ekberg O, Dahlberg L: Delayed gadolinium-enhanced MRI of cartilage (dGEMRIC) in early knee osteoarthritis. Magn Res Med 2003, 49(3):488-492.

66. Tiderius CJ, Svensson J, Leander P, Ola T, Dahlberg L: dGEMRIC (delayed gadolinium-enhanced MRI of cartilage) indicates adaptive capacity of human knee cartilage. Magn Res Med 2004, 51(2):286-290.

67. Gillis A, Bashir A, McKeon B, Scheller A, Gray ML, Burstein D: Magnetic resonance imaging of relative glycosaminoglycan distribution in patients with autologous chondrocyte transplants. Invest Radiol 2001, 36(12):743-748.

68. Vasara Al, Jurvelin JS, Peterson L, Kiviranta I: Arthroscopic Cartilage Indentation and Cartilage Lesions of Anterior Cruciate LigamentDeficient Knees. Am J Sports Med 2005, 33(3):408-414.

69. Kurkijarvi JE, Mattila L, Ojala RO, Vasara Al, Jurvelin JS, Kiviranta I, Nieminen MT: Evaluation of cartilage repair in the distal femur after autologous chondrocyte transplantation using T2 relaxation time and dGEMRIC. Osteoarthr Cartil 2007, 15(4):372-378.

70. Trattnig S, Marlovits S, Gebetsroither S, Szomolanyi P, Welsch GH, Salomonowitz E, Watanabe A, Deimling M, Mamisch TC: Three-dimensional delayed gadolinium-enhanced MRI of cartilage (dGEMRIC) for in vivo evaluation of reparative cartilage after matrix-associated autologous chondrocyte transplantation at 3.0 T: Preliminary results. J Magn Reson Imaging 2007, 26(4):974-982.

71. Trattnig S, Mamisch TC, Pinker K, Domayer S, Szomolanyi P, Marlovits S, KutschaLissberg F, Welsch GH: Differentiating normal hyaline cartilage from post-surgical repair tissue using fast gradient echo imaging in delayed gadolinium-enhanced MRI (dGEMRIC) at 3 Tesla. Eur Radiol 2008, 18(6):1251-1259.

72. David-Vaudey E, Ghosh S, Ries M, Majumdar S: T2 relaxation time measurements in osteoarthritis. Magn Reson Imaging 2004, 22(5):673-682.

73. Welsch GH, Mamisch TC, Domayer SE, Dorotka R, Kutscha-Lissberg F, Marlovits S, White LM, Trattnig S: Cartilage T2 assessment at 3-T MR imaging: in vivo differentiation of normal hyaline cartilage from reparative tissue after two cartilage repair procedures-initial experience. Radiology 2008, 247(1):154-161

74. Welsch GH, Zak L, Mamisch TC, Resinger C, Marlovits S, Trattnig S: ThreeDimensional Magnetic Resonance Observation of Cartilage Repair Tissue (MOCART) Score Assessed With an Isotropic Three-Dimensional True Fast Imaging With Steady-State Precession Sequence at 3.0 Tesla. Invest Radiol 2009, 44(9):603-612.

75. Trattnig S, Mamisch TC, Welsch GH, Glaser C, Szomolanyi P, Gebetsroither S, Stastny O, Horger W, Millington S, Marlovits S: Quantitative T2 Mapping of Matrix-Associated Autologous Chondrocyte Transplantation at 3 Tesla: An In Vivo Cross-Sectional Study. Invest Radiol 2007, 42(6):442-448.

76. Oneto JM, Ellermann J, LaPrade RF: Longitudinal evaluation of cartilage repair tissue after microfracture using T2-mapping: a case report with arthroscopic and MRI correlation. Knee Surg Sports Traumatol Arthrosc 2010, 18(11):1545-1550.

77. Tiderius, Carl Johan O, Lars Eric N, Fredrik D, Leif: Cartilage Glycosaminoglycan Loss in the Acute Phase After an Anterior Cruciate 
Ligament Injury: Delayed Gadolinium-Enhanced Magnetic Resonance Imaging of Cartilage and Synovial Fluid Analysis. Arthritis Rheum 2005, 52(1):120-127.

78. Multanen J, Rauvala E, Lammentausta E, Ojala R, Kiviranta I, Hakkinen A, Nieminen MT, Heinonen A: Reproducibility of imaging human knee cartilage by delayed gadolinium-enhanced MRI of cartilage (dGEMRIC) at 1.5 Tesla. Osteoarthr Cartil 2009, 17(5):559-564.

79. Hannila I, Raina SS, Tervonen O, Ojala R, Nieminen MT: Topographical variation of $\mathrm{T} 2$ relaxation time in the young adult knee cartilage at $1.5 \mathrm{~T}$. Osteoarthr Cartil 2009, 17(12):1570-1575.

80. Rantalainen T, Nikander R, Heinonen A, Daly RM, Sievanen H: An open source approach for regional cortical bone mineral density analysis. $J$ Musculoskelet Neuronal Interact 2011, 11(3):243-248.

81. Doube M, Klosowski MM, Arganda-Carreras I, Cordelieres FP, Dougherty RP, Jackson JS, Schmid B, Hutchinson JR, Shefelbine SJ: BoneJ: Free and extensible bone image analysis in ImageJ. Bone 2010, 47(6):1076-1079.

82. Rantalainen $T$, Nikander R, Daly RM, Heinonen A, Sievanen H: Exercise loading and cortical bone distribution at the tibial shaft. Bone 2011, 48(4): 786-791.

83. Uusi-Rasi K, Rauhio A, Kannus P, Pasanen M, Kukkonen-Harjula K, Fogelholm $\mathrm{M}$, Sievanen $\mathrm{H}$ : Three-month weight reduction does not compromise bone strength in obese premenopausal women. Bone 2010, 46(5):1286-1293.

84. Beck TJ, Ruff CB, Warden KE, Scott WW Jr, Rao GU: Predicting femoral neck strength from bone mineral data. A structural approach. Invest Radiol 1990, 25(1):6-18

85. Yoshikawa T, Turner CH, Peacock M, Slemenda CW, Weaver CM, Teegarden D, Markwardt P, Burr DB: Geometric structure of the femoral neck measured using dual-energy x-ray absorptiometry. J Bone Miner Res 1994, 9(7):1053-1064.

86. Beck T: Measuring the structural strength of bones with dual-energy $X-$ ray absorptiometry: principles, technical limitations, and future possibilities. Osteoporosis Int 2003, 14(5):81-88

87. Nikander R, Sievanen H, Ojala K, Kellokumpu-Lehtinen PL, Palva T, Blomqvist C, Luoto R, Saarto T: Effect of exercise on bone structural traits, physical performance and body composition in breast cancer patients-a 12 month RCT. J Musculoskelet Neuronal Interact 2012, 12(3):127-135.

88. Bellamy N, Buchanan WW, Goldsmith CH, Campbell J, Stitt LW: Validation study of WOMAC: a health status instrument for measuring clinically important patient relevant outcomes to antirheumatic drug therapy in patients with osteoarthritis of the hip or knee. J Rheumatol 1988, 15(12):1833-1840.

89. Roos EM, Roos HP, Ekdahl C, Lohmander LS: Knee injury and Osteoarthritis Outcome Score (KOOS)-validation of a Swedish version. Scand J Med SCi Sports 1998, 8(6):439-448.

90. Roos EM, Klassbo M, Lohmander LS: WOMAC osteoarthritis index. Reliability, validity, and responsiveness in patients with arthroscopically assessed osteoarthritis. Western Ontario and MacMaster Universities. Scand J Rheumatol 1999, 28(4):210-215.

91. Bekkers JE, de Windt TS, Raijmakers NJ, Dhert WJ, Saris DB: Validation of the Knee Injury and Osteoarthritis Outcome Score (KOOS) for the treatment of focal cartilage lesions. Osteoarthr Cartil 2009, 17(11):1434-1439.

92. Koli J, Multanen J, Häkkinen A, Kiviranta I, Kujala U, Heinonen A: Reliability of the Finnish versions of WOMAC and KOOS forms for knee osteoarthritis. Physiotherapy 2011, 2011(97):D203-204.

93. Hays RD, Sherbourne CD, Mazel RM: The RAND 36-Item Health Survey 1.0. Health Econ 1993, 2(3):217-227.

94. Aalto AM, Aro AR, Teperi J: RAND-36 terveyteen liittyvän elämänlaadun mittarina. Mittarin luotettavuus ja suomalaiset väestöarvot. Stakes, Sosiaali- ja terveysalan tutkimus- ja kehittämiskeskus, tutkimuksia 1999, 101:78.

95. Sipila S, Multanen J, Kallinen M, Era P, Suominen H: Effects of strength and endurance training on isometric muscle strength and walking speed in elderly women. Acta Physiol Scand 1996, 156(4):457-464.

96. Bassey EJ, Short $\mathrm{AH}$ : A new method for measuring power output in a single leg extension: feasibility, reliability and validity. Eur J Appl Physiol 1990, 60(5):385-390.

97. Portegijs E, Sipila S, Alen M, Kaprio J, Koskenvuo M, Tiainen K, Rantanen T: Leg extension power asymmetry and mobility limitation in healthy older women. Arch Phys Med Rehabil 2005, 86(9):1838-1842.

98. Rantalainen T, Linnamo V, Komi PV, Selanne H, Heinonen A: Seventy-yearold habitual volleyball players have larger tibial cross-sectional area and may be differentiated from their age-matched peers by the osteogenic index in dynamic performance. Eur J Appl Physiol 2010, 109(4):651-658.

99. Laukkanen RMT, Oja P, Pasanen ME, Vuori IM: Criterion validity of a twokilometer walking test for predicting the maximal oxygen uptake of moderately to highly active middle-aged adults. Scand J Med Sci Sports 1993, 3(4):267-272.

100. Laukkanen RM, Oja P, Ojala KH, Pasanen ME, Vuori IM: Feasibility of a 2-km walking test for fitness assessment in a population study. Scand J SoC Med 1992, 20(2):119-126.

101. KukkonenHarjula K, Laukkanen R, Vuori I, Oja P, Pasanen M, Nenonen A, UusiRasi K: Effects of walking training on health-related fitness in healthy middle-aged adults-a randomized controlled study. Scand J Med Sci Sports 1998, 8(4):236-242

102. Laukkanen $\mathrm{R}$, Oja P, Pasanen M, Vuori I: Validity of a two kilometre walking test for estimating maximal aerobic power in overweight adults. Int $J$ Obes Relat Metab Disord 1992, 16(4):263-268.

103. Sihvonen S, Era P: Test-retest reliability of easy and more demanding balance tests in young, middle-aged, and elderly participants. JAPA 1999, 7(3):312

104. Sihvonen SE, Sipila S, Era PA: Changes in postural balance in frail elderly women during a 4-week visual feedback training: a randomized controlled trial. Gerontology 2004, 50(2):87-95.

105. Pajala S, Era P, Koskenvuo M, Kaprio J, Tormakangas T, Rantanen T: Force platform balance measures as predictors of indoor and outdoor falls in community-dwelling women aged 63-76 years. J Gerontol A Biol Sci Med Sci 2008, 63(2):171-178.

106. UusiRasi K, Kannus P, Cheng S, Sievanen H, Pasanen M, Heinonen A, Nenonen A, Halleen J, Fuerst T, Genant H, Vuori I: Effect of alendronate and exercise on bone and physical performance of postmenopausal women: a randomized controlled trial. Bone 2003, 33(1):132-143.

107. Karinkanta S, Heinonen A, Sievanen H, UusiRasi K, Pasanen M, Ojala K, Fogelholm M, Kannus P: A multi-component exercise regimen to prevent functional decline and bone fragility in home-dwelling elderly women: randomized, controlled trial. Osteoporosis Int 2007, 18(4):453-462

108. Tegner $Y$, Lysholm J, Lysholm M, Gillquist J: A performance test to monitor rehabilitation and evaluate anterior cruciate ligament injuries. Am $J$ Sports Med 1986, 14(2):156-159.

109. Rinne MB, Pasanen ME, Vartiainen MV, Lehto TM, Sarajuuri JM, Alaranta HT: Motor performance in physically well-recovered men with traumatic brain injury. J Rehabil Med 2006, 38(4):224-229.

110. Cutlip RG, Mancinelli C, Huber F, DiPasquale J: Evaluation of an instrumented walkway for measurement of the kinematic parameters of gait. Gait Posture 2000, 12(2):134-138.

111. Bilney B, Morris $M$, Webster K: Concurrent related validity of the GAITRite walkway system for quantification of the spatial and temporal parameters of gait. Gait Posture 2003, 17(1):68-74.

112. Paterson $\mathrm{KL}$, Hill KD, Lythgo ND, Maschette $\mathrm{W}$ : The reliability of spatiotemporal gait data for young and older women during continuous overground walking. Arch Phys Med Rehabil 2008, 89(12):2360-2365.

113. van Uden CJ, Besser MP: Test-retest reliability of temporal and spatial gait characteristics measured with an instrumented walkway system (GAITRite). BMC Musculoskelet Disord 2004, 5:13.

114. Ainsworth BE, Haskell WL, Whitt MC, Irwin ML, Swartz AM, Strath SJ, O'brien WL, Bassett DRJ, Schmitz KH, Emplaincourt PO, Jacobs DRJ, Leon AS: Compendium of Physical Activities: an update of activity codes and MET intensities. Med Sci Sports Exerc 2000, 32(9):S498-S516.

115. Ainsworth BE, Haskell WL, Herrmann SD, Meckes N, Bassett DRJ, TudorLocke C, Greer JL, Vezina J, Whitt-Glover MC, Leon AS: Compendium of Physical Activities: A Second Update of Codes and MET Values. Med Sci Sports Exerc 2011, 43(8):1575-1581.

116. Borg GA: Psychophysical bases of perceived exertion. Med Sci Sports Exerc 1982, 14(5):377-381.

117. Poyhonen T, Kyrolainen H, Keskinen KL, Hautala A, Savolainen J, Malkia E: Electromyographic and kinematic analysis of therapeutic knee exercises under water. Clin Biomech 2001, 16(6):496-504.

118. Poyhonen T, Keskinen KL, Kyrolainen H, Hautala A, Savolainen J, Malkia E: Neuromuscular function during therapeutic knee exercise under water and on dry land. Arch Phys Med Rehabil 2001, 82(10):1446-1452.

119. Poyhonen T, Sipila S, Keskinen KL, Hautala A, Savolainen J, Malkia E: Effects of aquatic resistance training on neuromuscular performance in healthy women. Med Sci Sports Exerc 2002, 34(12):2103-2109. 
120. Valtonen A, Poyhonen T, Sipila S, Heinonen A: Effects of aquatic resistance training on mobility limitation and lower-limb impairments after knee replacement. Arch Phys Med Rehabil 2010, 91(6):833-839.

121. Valtonen A, Poyhonen T, Sipila S, Heinonen A: Maintenance of aquatic training-induced benefits on mobility and lower-extremity muscles among persons with unilateral knee replacement. Arch Phys Med Rehabil 2011, 92(12):1944-1950.

122. Poyhonen T, Keskinen KL, Hautala A, Malkia E: Determination of hydrodynamic drag forces and drag coefficients on human leg/foot model during knee exercise. Clin Biomech 2000, 15(4):256-260.

123. Gill SD, McBurney H, Schulz DL: Land-based versus pool-based exercise for people awaiting joint replacement surgery of the hip or knee: results of a randomized controlled trial. Arch Phys Med Rehabil 2009, 90(3):388-394.

124. Fransen M, Nairn L, Winstanley J, Lam P, Edmonds J: Physical activity for osteoarthritis management: a randomized controlled clinical trial evaluating hydrotherapy or Tai Chi classes. Arthritis Rheum 2007, 57(3): 407-414.

125. Sylvester KL: Investigation of the effect of hydrotherapy in the treatment of osteoarthritic hips. Clin Rehabil 1990, 4:223-228.

126. StenerVictorin ERPT, KruseSmidje CRPT, Jung KRPT: Comparison Between Electro-Acupuncture and Hydrotherapy, Both in Combination With Patient Education and Patient Education Alone, on the Symptomatic Treatment of Osteoarthritis of the Hip. Clin J Pain 2004, 20(3):179-185.

127. Wang T, Lee S, Liang S, Tung H, Wu SV, Lin Y: Comparing the efficacy of aquatic exercises and land-based exercises for patients with knee osteoarthritis. J Clin Nurs 2011, 20(17-18):2609-2622.

128. Silva LE, Valim V, Pessanha AP, Oliveira LM, Myamoto S, Jones A, Natour J: Hydrotherapy versus conventional land-based exercise for the management of patients with osteoarthritis of the knee: a randomized clinical trial. Phys Ther 2008, 88(1):12-21.

129. Wyatt FB, Milam S, Manske RC, Deere R: The Effects of Aquatic and Traditional Exercise Programs on Persons With Knee Osteoarthritis. J Strength Cond Res 2001, 15(3):337-340.

130. Green J, McKenna F, Redfern EJ, Chamberlain MA: Home exercises are as effective as outpatient hydrotherapy for osteoarthritis of the hip. Br J Rheumatol 1993, 32(9):812-815.

131. Hinman RS, Crossley KM: Patellofemoral joint osteoarthritis: an important subgroup of knee osteoarthritis. Rheumatology (Oxford) 2007, 46(7):10571062.

132. Bravo G, Gauthier P, Roy P, Payette H: Effects of an aquatic exercise program in osteopenic women. J Am Geriatr Soc 1996, 44(9):S14.

133. Rotstein $A$, Harush M, Vaisman N: The effect of a water exercise program on bone density of postmenopausal women. J Sports Med Phys Fitness 2008, 48(3):352-359.

134. Nissi MJ, Toyras J, Laasanen MS, Rieppo J, Saarakkala S, Lappalainen R, Jurvelin JS, Nieminen MT: Proteoglycan and collagen sensitive MRI evaluation of normal and degenerated articular cartilage. J Orthop Res 2004, 22(3):557-564.

135. Dunn TC, Lu Y, Jin H, Ries MD, Majumdar S: T2 relaxation time of cartilage at MR imaging: comparison with severity of knee osteoarthritis. Radiology 2004, 232(2):592-598.

136. Souza RB, Baum T, Wu S, Feeley BT, Kadel N, Li X, Link TM, Majumdar S: Effects of unloading on knee articular cartilage T1rho and T2 magnetic resonance imaging relaxation times: a case series. J Orthop Sports Phys Ther 2012, 42(6):511-520.

137. Haapala J, Arokoski J, Pirttimaki J, Lyyra T, Jurvelin J, Tammi M, Helminen HJ, Kiviranta I: Incomplete restoration of immobilization induced softening of young beagle knee articular cartilage after 50-week remobilization. Int J Sports Med 2000, 21(1):76-81.

138. Vanwanseele B, Lucchinetti E, Stussi E: The effects of immobilization on the characteristics of articular cartilage: current concepts and future directions. Osteoarthr Cartil 2002, 10(5):408-419.

\section{doi:10.1186/1471-2474-14-82}

Cite this article as: Waller et al:: Effects of a progressive aquatic resistance exercise program on the biochemical composition and morphology of cartilage in women with mild knee osteoarthritis: protocol for a randomised controlled trial. BMC Musculoskeletal Disorders 2013 14:82

\section{Submit your next manuscript to BioMed Central and take full advantage of:}

- Convenient online submission

- Thorough peer review

- No space constraints or color figure charges

- Immediate publication on acceptance

- Inclusion in PubMed, CAS, Scopus and Google Scholar

- Research which is freely available for redistribution 